\title{
Research on Performance Evaluation of Tidal Energy Turbine under Variable Velocity
}

\author{
Chuhua Jiang ${ }^{1}$, Xuedao Shu ${ }^{1, *}$, Junhua Chen ${ }^{2}$, Lingjie Bao ${ }^{1}$ and Hao $\mathrm{Li}^{2}$ \\ 1 School of Mechanical Engineering and Mechanics, Ningbo University, Ningbo 315211, China; \\ jiangchuhua@nbu.edu.cn (C.J.); baolingjie163@163.com (L.B.) \\ 2 School of Mechanical Engineering and Automation, College of Science \& Technology, Ningbo University, \\ Cixi 315300, China; cjh@nit.net.cn (J.C.); 187lihao@163.com (H.L.) \\ * Correspondence: shuxuedao@nbu.edu.cn
}

Received: 26 October 2020; Accepted: 26 November 2020; Published: 30 November 2020

\begin{abstract}
Aiming at the performance evaluation problem of tidal energy turbines in the application of periodic time-varying flow velocity, with the goal of maximizing the efficiency of energy harvesting in practical applications, an evaluation system combining the characteristics of flow velocity changes in practical applications is proposed. After long-term monitoring of tidal current flow velocity in the applied sea area, the actual measured tidal current periodic flow velocity is divided into several flow velocity segments by using statistical segmentation, and the evaluation flow velocity of each flow velocity segment and its time proportion in the tidal current cycle are obtained. A test device with constant torque regulation is built, and capture power tests of different torque loads are carried out under each evaluation flow rate. After comparison, the maximum captured power at each evaluation flow rate is determined. We calculate the weight based on the time proportion of each evaluation flow velocity and obtain the turbine average power of the tidal cycle, thereby evaluating the overall energy capture performance of the turbine under the periodic time-varying flow velocity. Finally, the application test of the turbine in the actual sea area shows that the thin-walled airfoil turbine is more suitable for the sea area, which is the same as the pool evaluation result. The result shows that the evaluation system is reliable and effective and has significance for guiding practical engineering.
\end{abstract}

Keywords: tidal current energy; turbine; periodic time-varying; evaluation flow velocity; capture power

\section{Introduction}

The energy problem is urgent throughout the world today. The over-exploitation and utilization of fossil energy has caused a serious threat to modern civilization and the world economy [1]. Tidal energy is a kind of renewable energy contained in the ocean [2] and creates no pollution. Its predictability is strong, and the resources are abundant [3,4]; countries around the world are competing to develop the use of tidal energy, which plays a vital role in alleviating the problem of energy shortages $[5,6]$. A water turbine is the most critical component of tidal current energy capture, and its energy capture performance directly affects the efficiency of tidal energy utilization $[7,8]$. Scholars from various countries usually use numerical calculation methods to evaluate the performance of water turbines [9-11]. Due to the complex flow forces of hydraulic turbines, it is difficult to accurately simulate the actual force in numerical calculations, and the use of model experiments is more reliable. It is extremely important to establish a reliable performance evaluation system for the turbine [12-14]. Day, A.H. summarizes the key issues of physical model testing of marine renewable energy systems and introduces some key research in modeling research [15]. Bachant Peter studied the effect of Reynolds number on the performance of hydraulic turbines through experiments in a large laboratory [16]. 
Quan-kun Xu designed and built a $60 \mathrm{KW}$ horizontal axis tidal current power generation system and carried out tests in the application sea area to evaluate its energy capture performance [17].

At present, when studying the performance tests of hydraulic turbines, both numerical research and model experimental research are basically compared at a certain flow rate. For example, Shahram Derakhshan [18] studied the blade rotation angle by experiment and numerical simulation under a conventional flow rate. In terms of performance effects, Benoît Gaurier [19] studied the effects of turbulence on the performance of hydraulic turbines at a certain flow rate. Abutunis, A. [20] studied the effects of turbine mechanism and the number of blades on its performance at a certain flow rate. Ma Yong studied the effect of platform oscillation frequency and oscillation amplitude on the performance of hydraulic turbines through numerical simulation and experimental verifications [21]. Ren Yirua [22] and others designed a new type of hydraulic turbine with winglets, and studied the influence of the length, tip chord and inclination angle of the winglet on the hydrodynamic performance of the winglet under the optimal tip speed ratio. However, in practical engineering applications, the tidal flow rate is not always constant at a specific flow rate, but changes periodically. Therefore, simply evaluating the performance of the turbine at a specific flow rate to reflect the energy capture performance of the turbine in practical applications is one-sided. Moreover, in the evaluation process of a hydraulic turbine, usually only the tip speed ratio is controlled [23], without considering the influence of torque, and it is difficult to accurately evaluate the best performance of the turbine.

In order to more accurately reflect the comprehensive performance of hydraulic turbines under the application of time-varying flow velocity in the sea area, research on the turbine performance evaluation system based on the statistical segmentation of the time-varying flow velocity data of the applied sea tidal cycle was carried out, and a statistical segmentation of the time-varying flow velocity of the tide cycle was creatively proposed. The method can effectively perform statistical segmentation on the flow velocity data of the applied sea area and determine the evaluation flow velocity of the turbine evaluation system and the time proportion of the flow velocity in the tidal cycle. This added a servo motor to the evaluation device to accurately adjust the torque of the test device [24], carried out a variety of torque loading tests at various flow rate [25], to ensure that the maximum power of the turbine under the evaluation flow rate was accurately measured, and then combined the time weight of each evaluation flow rate to convert the tidal flow cycle. The average power reflects the energy capture performance of the turbine in practical applications. A list of symbols and their units used in the present study is given in Table 1.

Table 1. Nomenclature.

\begin{tabular}{|c|c|c|c|}
\hline Symbol & Description & Symbol & Description \\
\hline $\mathrm{V}$ & $\begin{array}{l}\text { Maximum flow velocity } \\
\text { of tidal current }(\mathrm{m} / \mathrm{s})\end{array}$ & $\rho$ & Water density $\left(\mathrm{kg} / \mathrm{m}^{3}\right)$ \\
\hline a & $\begin{array}{c}\text { Flow rate segment } \\
\text { interval (-) }\end{array}$ & $S$ & Sweeping area $\left(\mathrm{m}^{2}\right)$ \\
\hline$A_{i}$ & $\begin{array}{l}\text { Percentage of flow } \\
\text { velocity in section i to } \\
\text { tidal current cycle (-) }\end{array}$ & $v$ & Water flow velocity $(\mathrm{m} / \mathrm{s})$ \\
\hline$P_{M}$ & $\begin{array}{l}\text { Instantaneous incoming } \\
\text { power }(\mathrm{W})\end{array}$ & $M$ & Output torque (Nm) \\
\hline $\mathrm{P}$ & $\begin{array}{c}\text { Instantaneous incoming } \\
\text { power }(\mathrm{W})\end{array}$ & $\omega$ & $\begin{array}{l}\text { Turbine angular velocity } \\
(\mathrm{rad} / \mathrm{s})\end{array}$ \\
\hline$P_{i}$ & $\begin{array}{l}\text { Ith segment evaluation } \\
\text { maximum capture } \\
\text { power(W) }\end{array}$ & $n$ & Turbine speed (r/min) \\
\hline $\mathrm{P}_{a}$ & $\begin{array}{l}\text { Average power flow } \\
\text { cycle }(W)\end{array}$ & TSR & Tip speed ratio \\
\hline$C_{P}$ & Power coefficient & $R$ & Blade radius \\
\hline
\end{tabular}




\section{Principles and Methods of Turbine Performance Evaluation}

\subsection{Principles of Turbine Performance Evaluation}

The ultimate goal of water turbine performance evaluation research is to improve the efficiency of energy harvesting in practical applications. Currently, the performance evaluation of tidal current energy turbines is usually carried out at a certain design flow rate, but this detection method faces great problems. The water turbine is in practical application. The average capture power is much smaller than the captured power measured at the design flow rate. The fundamental reason for this consequence is that the flow rate in the actual application sea area changes periodically, so the performance of the turbine at the design flow rate cannot fully represent the application performance in the sea.

In this regard, before the performance evaluation of the hydraulic turbine, the flow velocity of the application sea area is monitored, the flow velocity data of the complete rising and falling tide cycle representative of the application sea area is obtained, and the tidal cycle velocity data is divided by statistics to obtain several flow velocity sections and each flow velocity. The period of time accounts for the percentage of the tidal cycle. The average value of each flow rate section is used as the evaluation flow rate of the turbine. Then, a turbine performance test is carried out at each evaluation flow rate, and the different torques are adjusted at the same flow rate to perform multiple tests to ensure that the maximum flow rate is obtained. We capture the power, and finally calculate the average captured power of the turbine tidal cycle by combining the maximum power of each flow rate section and its time proportion. The flowchart is shown in Figure 1.

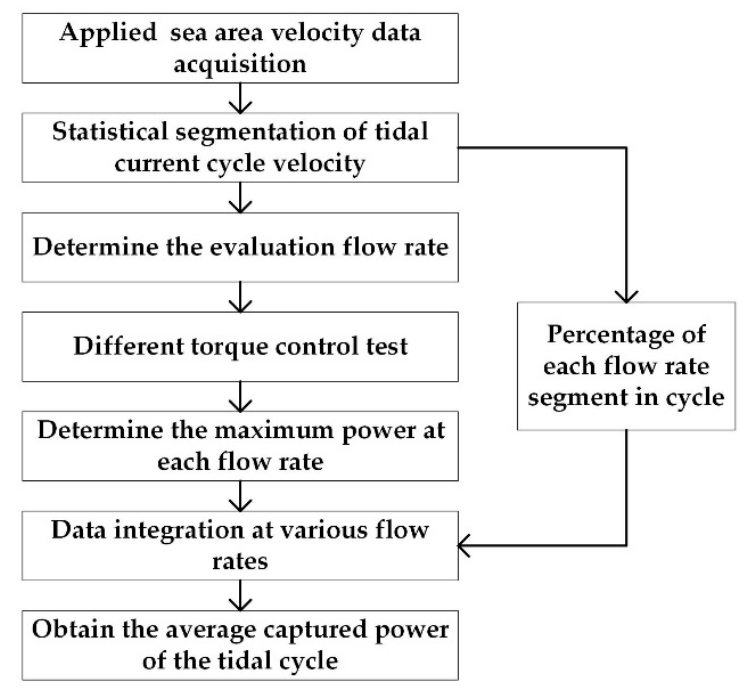

Figure 1. Turbine performance evaluation flowchart.

\subsection{Method for Dividing the Cycle Velocity of Tidal Current}

The following segmentation method is proposed for the statistical segmentation of tidal current cycle data in the application sea area: we select the working hours of tidal energy turbines in a certain application sea area, and divide the working hours of the turbines into different working cycles. For example, the working hours of the turbines can be divided into the annual tidal energy capture. There are the four quarters, and each quarter can be divided into high tide period and flat tide period. The daily change of the sea area flow velocity in each cycle should be similar. The sea area flow velocity in each working cycle in the sea area shall be monitored at fixed intervals throughout the day. We summarize and obtain representative complete flow velocity data of the rising and falling tide cycles. 
We sort the flow velocity data from small to large, and obtain the maximum flow velocity $\mathrm{V}$. After testing, when the flow velocity is less than $0.6 \mathrm{~m} / \mathrm{s}$, the turbine does not break through the starting torque and is in a non-working state. Therefore, the data less than $0.6 \mathrm{~m} / \mathrm{s}$ are regarded as a section and no test is performed. The rest are initially uniformly divided into 11 segments, and the segment interval $a$ is calculated as follows:

$$
a=\frac{\mathrm{V}-0.6}{10}
$$

In large pools, dragging is usually used to simulate water flow. Affected by factors such as track flatness, traction chain deformation, drive motor transmission mechanism, etc., the simulated water flow velocity has an error of two decimal places; the geometric size of the hydraulic turbine test model is relatively small, and the water flow is in the range of 0.1 The change in the internal pressure has little effect on the output result; the power of the hydraulic turbine is transmitted to the measuring device through the transmission mechanism, and it is difficult for the measuring device to accurately measure the small value change, which is affected by the above three points. The minimum value of $a$ is 0.1 , and the rounding of $a$ are $0.1,0.2,0.3$ for convenience.

The flow rate measuring instrument performs working measurement at fixed intervals, so each flow rate data point represents an interval time. We count the number of data points for each flow rate section to get the duration of the flow rate section. We divide by the total number of flow rate data points to obtain the time proportion of each flow rate section. Part $i$ flow rates accounting for the percentage of the tidal current cycle $A_{i}$ is calculated as follows:

$$
A_{i}=\frac{\text { Number of data points in flow velocity sec tion }}{\text { Total number of flow data points }} \times 100 \%
$$

After the initial segmentation of the flow velocity, we calculate the proportion of each segment of time, and then further optimize the segmentation to remove the velocity segment less than $0.6 \mathrm{~m} / \mathrm{s}$. If $A_{i}<2 \%$, it means that the velocity of this segment has a very short time and the result has little effect on overall performance, and it can be combined with the adjacent velocity segment. Also, we can appropriately reduce the number of experiments; if $A_{i}>30 \%$, it means that the flow rate of this section takes a very long time; we can subdivide the section, increase the number of experiments, and improve the accuracy of the test power; the optimized comparison parameters can be adjusted appropriately according to the situation. After determining each flow rate section, we use the average value of the flow rate section as the evaluation flow velocity [26]. The segmentation process is shown in Figure 2, and the segmentation results are shown in Table 2.

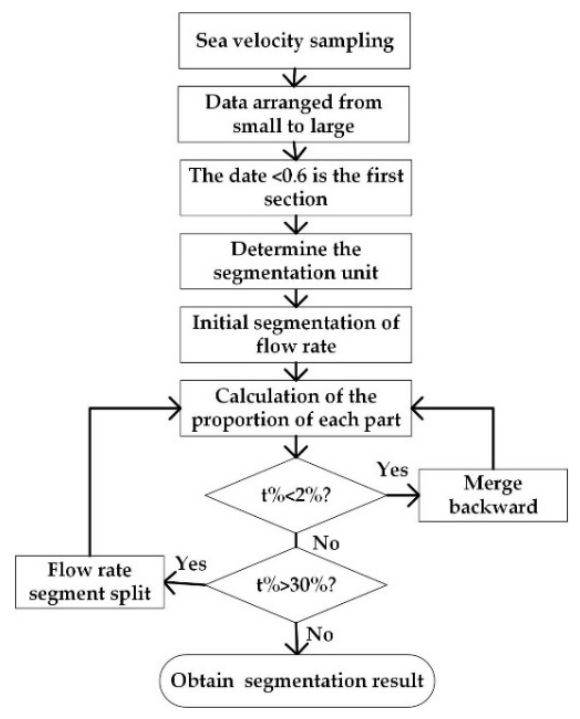

Figure 2. Tidal current period velocity segmentation flowchart. 
Table 2. Statistical segmentation results of sea area flow velocity.

\begin{tabular}{cccc}
\hline $\begin{array}{c}\text { Sea Area Velocity } \\
\text { Section }\end{array}$ & Velocity Range & $\begin{array}{c}\text { Percentage of } \\
\text { Time (\%) }\end{array}$ & $\begin{array}{c}\text { Evaluation } \\
\text { Flow Rate } \\
(\mathbf{m} / \mathbf{s})\end{array}$ \\
\hline 0 & {$[\mathbf{0}, \mathbf{0 . 6}$} & $A_{0}$ & No test \\
1 & {$\left[0.6, \mathrm{X}_{1}\right)$} & $A_{1}$ & $\left(0.6+\mathrm{X}_{1}\right) / 2$ \\
2 & {$\left[\mathrm{X}_{1}, \mathrm{X}_{2}\right)$} & $A_{2}$ & $\left(\mathrm{X}_{1}+\mathrm{X}_{2}\right) / 2$ \\
$\ldots$ & $\ldots$ & $\ldots$ & $\ldots$ \\
$i$ & {$\left[\mathrm{X}_{\mathrm{i}}, \mathrm{X}_{\mathrm{i}+1}\right)$} & $A_{i}$ & $\left(\mathrm{X}_{\mathrm{i}}+\mathrm{X}_{\mathrm{i}+1}\right) / 2$ \\
$\ldots$ & $\ldots$ & $\ldots$ & $\ldots$ \\
$\mathrm{n}-1$ & {$\left[\mathrm{X}_{\mathrm{n}-2}, \mathrm{X}_{\mathrm{n}-1}\right)$} & $A_{n-1}$ & $\left(\mathrm{X}_{\mathrm{n}-2}+\mathrm{X}_{\mathrm{n}-1}\right) / 2$ \\
$\mathrm{n}$ & {$\left[\mathrm{X}_{\mathrm{n}-1}, \mathrm{X}_{\mathrm{n}}\right)$} & $A_{n}$ & $\left(\mathrm{X}_{\mathrm{n}-1}+\mathrm{X}_{\mathrm{n}}\right) / 2$ \\
\hline
\end{tabular}

\subsection{Evaluation Method of Energy Capture Performance}

The calculation formula of the captured power $P$ of the hydraulic turbine is obtained by the formula of the water flow energy $P_{M}$ and the power coefficient $C_{P}$ [27]:

$$
\begin{gathered}
P_{M}=\frac{1}{2} \rho S v^{3} \\
C_{P}=\frac{P}{P_{M}} \\
P=\frac{1}{2} \rho S v^{3} C_{P}
\end{gathered}
$$

where $\rho$ is the density of seawater, $S$ is the swept area of impeller, $v$ is the velocity of seawater, and $C_{P}$ is the power coefficient, which can reflect the capture efficiency of the turbine. It can be seen that $S$ is the key parameter affecting the captured power at the same flow rate. When comparing different turbines, it is necessary to ensure that $S$ is the same.

The relationship between capture power $P$ and torque $M$ and rotating speed $\omega$ is as follows [28]:

$$
P=M \times \omega=M \times \frac{2 \pi n}{60}=M n \frac{\pi}{30}
$$

where $M$ is the torque output of the turbine, $\omega$ is the angular velocity of the turbine, and $n$ is the rotational speed of the turbine. It can be seen that the capture power is related to the output torque and speed of the turbine. Under the same situation, the two influence each other. Researchers usually only study the effect of the tip speed ratio on the capture power. However, the actual control process is through the regulation of the capture power. The output load can be installed to regulate the output torque and indirectly regulate the speed to obtain the set tip speed ratio. To obtain the tip speed ratio $T S R$, the formula is as follows:

$$
T S R=\frac{\omega R}{v}
$$

where $R$ is the blade radius, $v$ is the water flow velocity. During this test, the output torque is directly used as the control variable, and various torque loading tests are carried out under each evaluation flow rate. We calculate the captured power from the speed and torque, and compare the results of each group of experiments to determine the maximum captured power of the turbine at each evaluation flow rate, denoted as $P_{i}(i=1, \ldots, n)$.

$\mathrm{P}_{\mathrm{i}}$ corresponds to the flow rate time ratio $A_{i}$, and the two are weighted to calculate the average captured power $\mathrm{P}_{a}$ of the turbine in the tidal current cycle in the applied sea area:

$$
\mathrm{P}_{a}=\mathrm{P}_{1} \times A_{1}+\mathrm{P}_{2} \times A_{2}+\ldots+\mathrm{P}_{\mathrm{i}} \times A_{i}+\ldots+\mathrm{P}_{\mathrm{n}} \times A_{n}
$$


The energy capture performance of a turbine with the same sweep flow area under periodic time-varying flow velocity can be measured by the average power of the flow velocity cycle.

\section{Turbine Performance Evaluation Device}

The design scheme of the hydraulic turbine performance evaluation device is shown in Figure 3. The hydraulic turbine to be tested is fixed on the support frame through the central shaft, and the input drive shaft is driven by the chain. The drive shaft is equipped with a coupling, a torque speed sensor, a reducer and a servo motor as shown in Figure 4. After the servo motor is connected to the evaluation control box, the torque and speed data are collected and the servo motor is controlled. The evaluation control box is equipped with a wireless AP (Access Point) to establish a wireless connection between the measurement and control system and the $\mathrm{PC}$, which is convenient for data storage and evaluation device control.

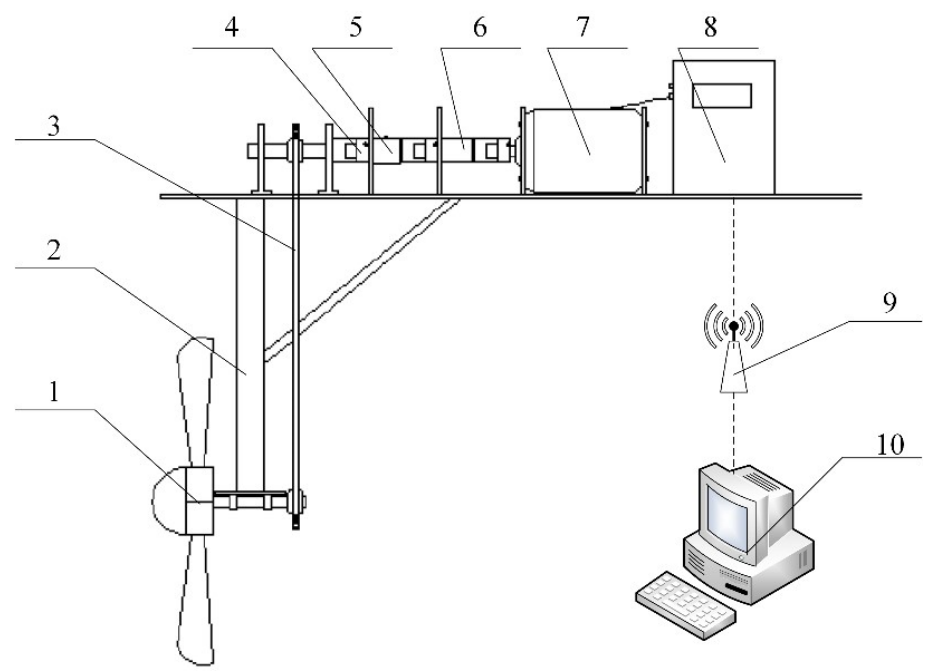

Figure 3. Schematic diagram of turbine performance evaluation device. 1 . The turbine under test; 2. Support frame; 3. Chain drive; 4. Coupling; 5 . Torque sensor; 6. Speed increaser; 7. Servo motor; 8. Evaluation control box; 9 . Wireless transmission; 10. PC terminal.

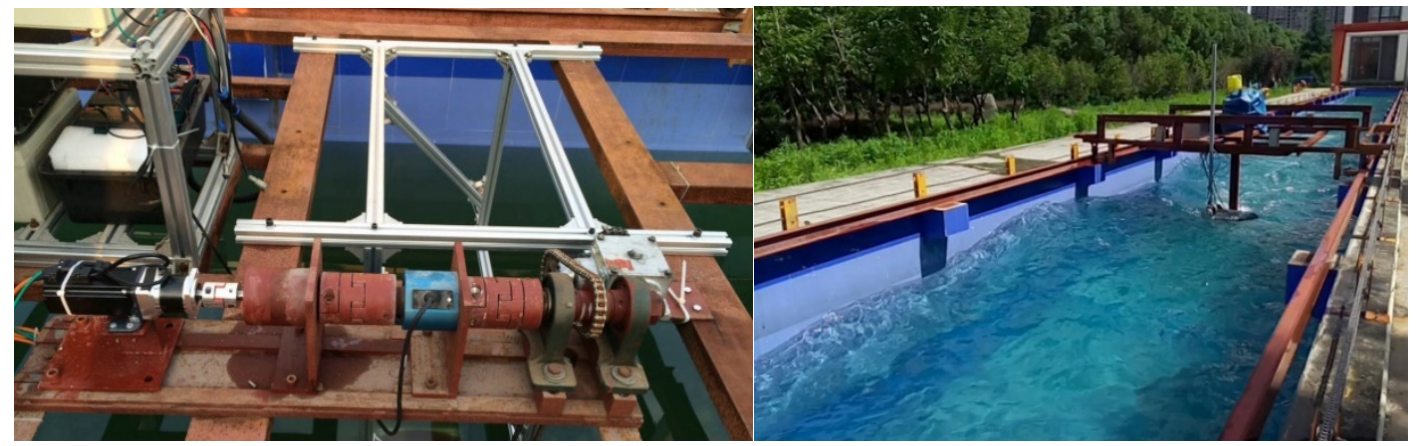

(a)

(b)

Figure 4. (a) Physical image of evaluation device, (b) The experimental pool.

The evaluation device measures the actual speed and torque through a dynamic torque sensor to calculate the captured power of the turbine. The evaluation device realizes constant torque damping control through a servo motor. A reducer is installed between the servo motor and the torque sensor. We determine the transmission ratio of the reducer according to the maximum output torque of the selected motor and the ideal torque of the turbine at the maximum flow rate, the total reduction ratio is 1:40. There is a certain deviation between the torque controlled by the motor and the actual torque of 
the drive shaft. The actual measured value of the torque sensor is used as the control object. The main equipment and functions of the performance evaluation device are shown in Table 3.

Table 3. Main equipment and function description of performance evaluation device.

\begin{tabular}{cccc}
\hline Equipment Name & Description & Equipment Name & Description \\
\hline Chain drive & $\begin{array}{c}\text { Turbine power transmission } \\
\text { (transmission ratio 1:1) } \\
\text { Dynamic torque } \\
\text { sensor sensor } \\
\text { Servo motor } \\
\text { and speed (range 0-100 r/min) } \\
\text { Constant torque damping control } \\
\text { (power 750 W) }\end{array}$ & $\begin{array}{c}\text { PLC (Programmable } \\
\text { Logic Controller) }\end{array}$ & Control servo motor \\
Reducer & $\begin{array}{c}\text { Connect test equipment and } \\
\text { damping control equipment } \\
\text { (transmission ratio 1:40) }\end{array}$ & Wireless AP & 5-port PoE power switch \\
& Industrial PC & $\begin{array}{c}\text { Data wireless } \\
\text { transmission (UBNT M2) }\end{array}$ \\
data control and \\
storage
\end{tabular}

\section{Turbine Pool Evaluation and Applied Sea Trial}

\subsection{Applied Sea Area Velocity Acquisition and Statistical Segmentation}

In order to test the practical application effect of the hydraulic turbine performance evaluation system proposed in this article, we firstly sampled the seawater velocity in the actual application sea area. The experimental sea area was located in the area of Xiangshan Shipu in the East China Sea. We set up two flow meters evenly at the sea area test point. We measured flow rate data every 10 minutes. The average value of two flow meters was used as the sea area average flow rate within 10 minutes of the detection period, some data are shown in Table 4, after long-term sampling, the flow rate data representing the complete cycle of rising and falling tides was obtained, as shown in Figure 5.

Table 4. Flow velocity data for a certain period of time.

\begin{tabular}{cccccccc}
\hline $\begin{array}{c}\text { Serial } \\
\text { Number }\end{array}$ & $\begin{array}{c}\text { Flow } \\
\text { Meter1 }\end{array}$ & $\begin{array}{c}\text { Flow } \\
\text { Meter2 }\end{array}$ & $\begin{array}{c}\text { Average } \\
\text { Velocity }\end{array}$ & $\begin{array}{c}\text { Serial } \\
\text { Number }\end{array}$ & $\begin{array}{c}\text { Flow } \\
\text { Meter1 }\end{array}$ & $\begin{array}{c}\text { Flow } \\
\text { Meter2 }\end{array}$ & $\begin{array}{c}\text { Average } \\
\text { Velocity }\end{array}$ \\
\hline 1 & 0.253 & 0.353 & 0.303 & 8 & 1.356 & 1.297 & 1.327 \\
2 & 0.514 & 0.534 & 0.524 & 9 & 1.340 & 1.472 & 1.406 \\
3 & 0.629 & 0.671 & 0.650 & 10 & 1.524 & 1.392 & 1.458 \\
4 & 0.765 & 0.641 & 0.703 & 11 & 1.524 & 1.586 & 1.555 \\
5 & 0.832 & 0.809 & 0.820 & 12 & 1.528 & 1.501 & 1.515 \\
6 & 0.975 & 1.064 & 1.019 & 13 & 1.423 & 1.421 & 1.422 \\
7 & 1.176 & 1.118 & 1.147 & 14 & 1.397 & 1.403 & 1.400 \\
\hline
\end{tabular}

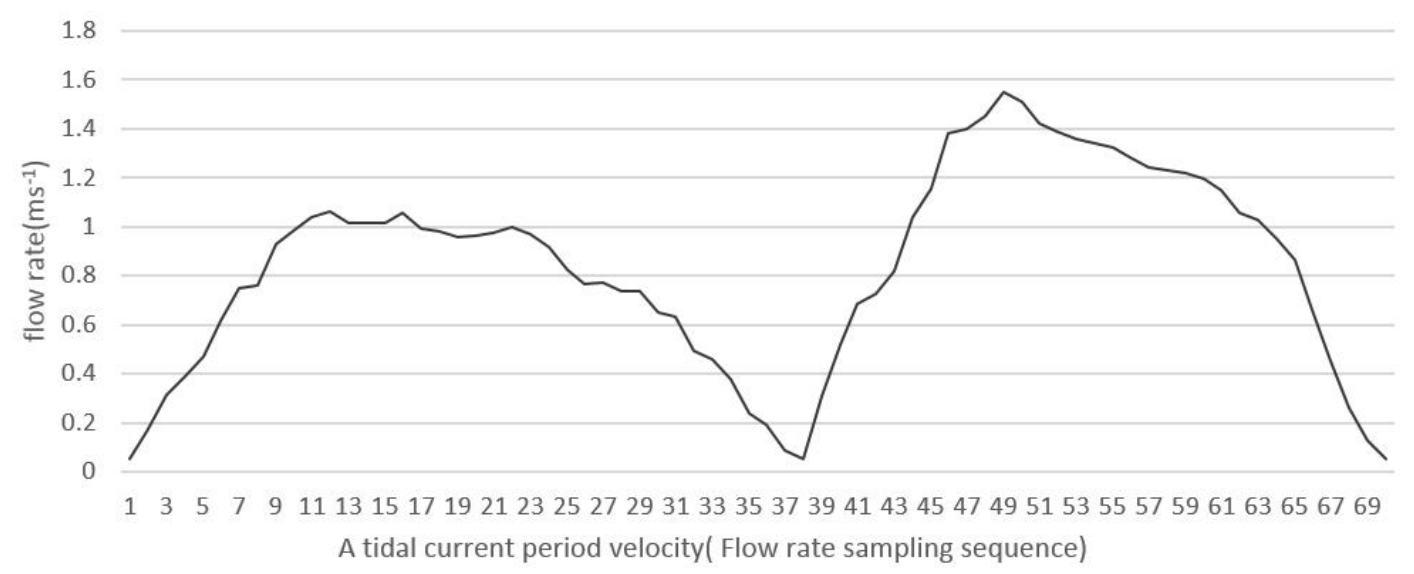

Figure 5. A tidal current period velocity in the applied sea area. 
We performed statistical segmentation on the tidal current cycle velocity data, and the maximum seawater velocity was $1.55 \mathrm{~m} / \mathrm{s}$, and the segmentation unit $a$ should be 0.1 . When the velocity was less than $0.6 \mathrm{~m} / \mathrm{s}$, the turbine did not start and no test was required. The final sea area velocity segmentation result is shown in Table 5 .

Table 5. Results of segmentation of experimental sea area velocity.

\begin{tabular}{cccc}
\hline $\begin{array}{c}\text { Sea Area } \\
\text { Velocity Section }\end{array}$ & Velocity Range & $\begin{array}{c}\text { Percentage of } \\
\text { Time (\%) }\end{array}$ & $\begin{array}{c}\text { Evaluation } \\
\text { Flow Rate } \\
(\mathbf{m} / \mathbf{s})\end{array}$ \\
\hline 0 & {$[0.0,0.6)$} & 25.71 & - \\
1 & {$[0.6,0.7)$} & 7.14 & 0.65 \\
2 & {$[0.7,0.8)$} & 10.00 & 0.75 \\
3 & {$[0.8,0.9)$} & 4.29 & 0.85 \\
4 & {$[0.9,1.0)$} & 15.71 & 0.95 \\
5 & {$[1.0,1.1)$} & 12.86 & 1.05 \\
6 & {$[1.1,1.2)$} & 4.29 & 1.15 \\
7 & {$[1.2,1.3)$} & 5.71 & 1.25 \\
8 & {$[1.3,1.4)$} & 7.14 & 1.35 \\
9 & {$[1.4,1.5)$} & 4.29 & 1.45 \\
10 & {$[1.5,1.6)$} & 2.86 & 1.55 \\
\hline
\end{tabular}

\subsection{Turbine Pool Evaluation}

The three types of turbines evaluated by the pool were NACA airfoil turbines, thin-wall airfoil turbines and S-type turbines that are currently captured by the current tide, as shown in Figure 6. According to similarity theory [29] and the test site conditions, the basic dimensions of the three turbines are designed. Other turbine parameters are set according to the current common dimensions. NACA airfoil turbines and thin-walled airfoil turbines use the same installation platform with a blade radius of $0.55 \mathrm{~m}$; because the $S$-type turbine is a resistance-type vertical axis for hydraulic turbines, the first two turbine installation platforms cannot be used. We used aluminum profiles to build the installation platforms. The blade diameter was $0.89 \mathrm{~m}$, the height to diameter ratio was 1.2 , and the height was $1.07 \mathrm{~m}$, to ensure that the sweeping area $\mathrm{S}$ of the three blades was $0.95 \mathrm{~m}^{2}$. The energy was transferred to the test device through a chain drive with a 1:1 transmission ratio. The basic parameters of the turbine are shown in Table 6.

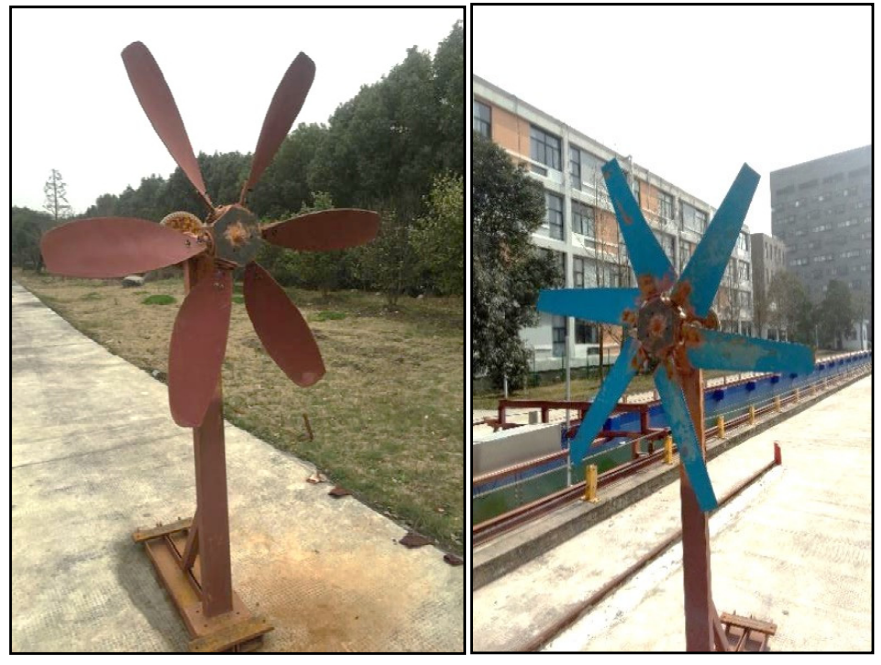

(a) (b)

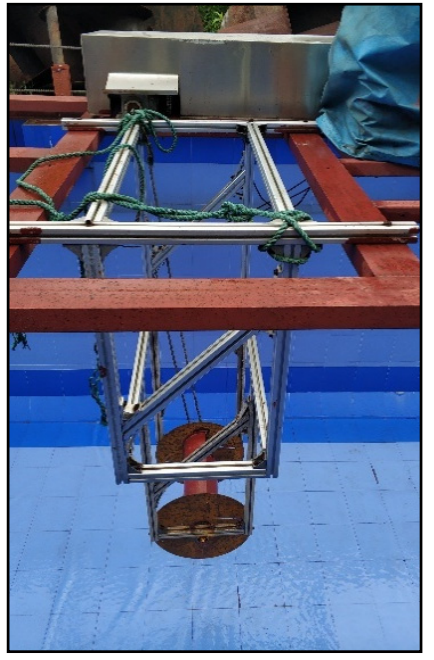

(c)

Figure 6. Physical image of hydraulic turbine model: (a) thin-walled airfoil, (b) NACA airfoil, (c) Savonius type. 
Table 6. Basic parameters of the turbine.

\begin{tabular}{cccccc}
\hline \multicolumn{2}{c}{ Thin-Walled Airfoil } & \multicolumn{2}{c}{ NACA Airfoil } & \multicolumn{2}{c}{ Savonius Type } \\
\hline Number of blades & 6 & Number of blades & 6 & Number of blades & 2 \\
Blade radius & $0.55 \mathrm{~m}$ & Blade radius & $0.55 \mathrm{~m}$ & Blade diameter & $0.89 \mathrm{~m}$ \\
Wheel diameter & $0.16 \mathrm{~m}$ & Wheel diameter & $0.16 \mathrm{~m}$ & Blade height & $1.2 \mathrm{~m}$ \\
Pitch angle & $12^{\circ}$ & Pitch angle & $12^{\circ}$ & Overlap rate & 0.11 \\
\hline
\end{tabular}

The performance evaluation of the water turbine was carried out in a towed experimental pool with a length of $70 \mathrm{~m}$, a width of $4 \mathrm{~m}$ and a depth of $2 \mathrm{~m}$. Both sides above the pool were equipped with rails, the trolley was framed on the track, the evaluation device and the water turbine were installed on the trolley, one end of the pool was equipped with a high-power servo motor to drive the sprocket on both sides of the track to rotate synchronously, and the other end of the pool was equipped with a corresponding The driven wheel consisted of a sprocket, a chain and a trolley forming a closed-loop chain drive drag device to simulate water flow to carry out experiments. Since the pool used a drag method to simulate ocean currents, each test had a trailer acceleration section, a constant velocity section, and a deceleration section. Therefore, it was impossible to complete multiple torque control experiments in one test. In this regard, the test was carried out in sequence by controlling different torques at the same flow rate. Each test took the data of the 10-40 s constant speed section of the trailer operation. The sampling device could sample 10 times per second and measure 300 sets of torques data and speed data each time from which the average power of each test was obtained. Eight tests were carried out at each flow rate. The constant torque output of the servo motor controlled the torque of the hydraulic turbine and indirectly controlled the speed of the turbine. The torque control made the turbine tip speed ratio change between 0.6-1.6, with an interval of 0.1. Through the comparison of various torque control tests at each flow rate, the maximum captured power at each flow rate was obtained.

After 240 effective tests, the maximum capture power of the three turbines was determined at each flow rate. By calculating the corresponding power coefficients, as shown in Figure 7, it can be seen that the power coefficients of the three turbines first increase and then decrease as the flow rate increases. The power coefficient of the S-type turbine is the largest at a flow rate of $0.85 \mathrm{~m} / \mathrm{s}$, reaching 0.35 , the power coefficient of the thin-walled airfoil turbine is the largest at a flow rate of $1.05 \mathrm{~m} / \mathrm{s}$, reaching 0.36, and the power coefficient of the NACA airfoil turbine is at a flow rate of $1.35 \mathrm{~m} / \mathrm{s}$. The maximum value is 0.35 . It can be seen that various hydraulic turbines have their own corresponding optimal flow rates to make their performance optimal, but the actual sea flow rate is time-varying, and the overall performance of water turbine energy capture needs to consider the actual sea flow rate change and the proportion of time. It can be seen from the figure that the S-type turbine is more suitable for long-term low-velocity waters, NACA airfoil turbines are more suitable for long-term high-velocity waters, and thin-walled airfoil turbines are suitable for waters where the velocity is between the first two.

Combined with the actual sea area flow rate statistics segmentation table, we have drawn the maximum power and time proportion diagram under each flow rate. As shown in Figure 8, the maximum power is the NACA airfoil turbine at a flow rate of $1.55 \mathrm{~m} / \mathrm{s}$, but the time for this high velocity to appear in this area is extremely short. According to Equation (8), the average power of the three turbines under the tidal period are obtained. As shown in Figure $9, P_{T}>P_{N A C A}>P_{S}$, considering the actual sea area flow velocity changes, the thin-walled airfoil turbine is more suitable for this sea area. Therefore, the performance evaluation of a hydraulic turbine cannot be based on the optimal performance at a certain flow rate, but should be combined with the actual application sea area flow rate data, and we calculate the average power of the turbine tidal period on a judgment basis, so as to optimize the energy capture efficiency in the application process. 


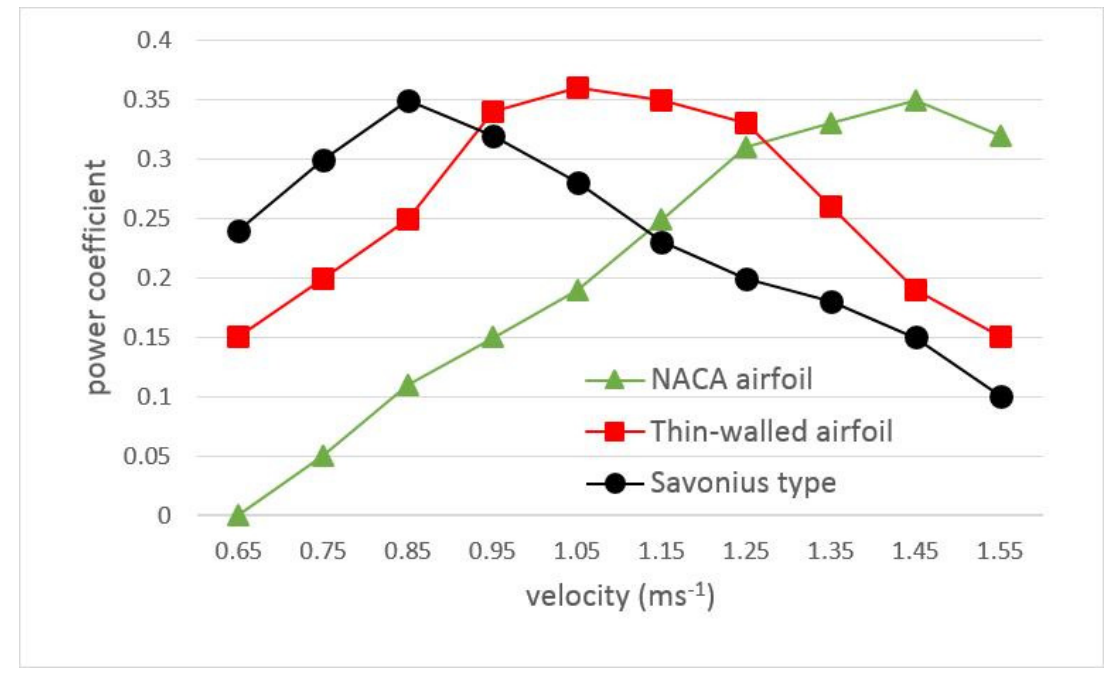

Figure 7. Power coefficients of three kinds of turbine at different flow rates.

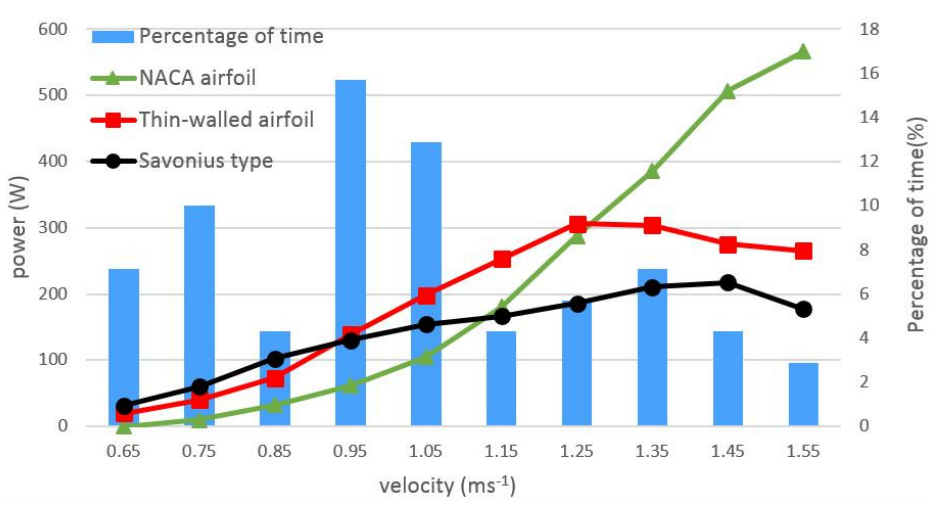

Figure 8. Maximum power and time ratio at each flow rate.

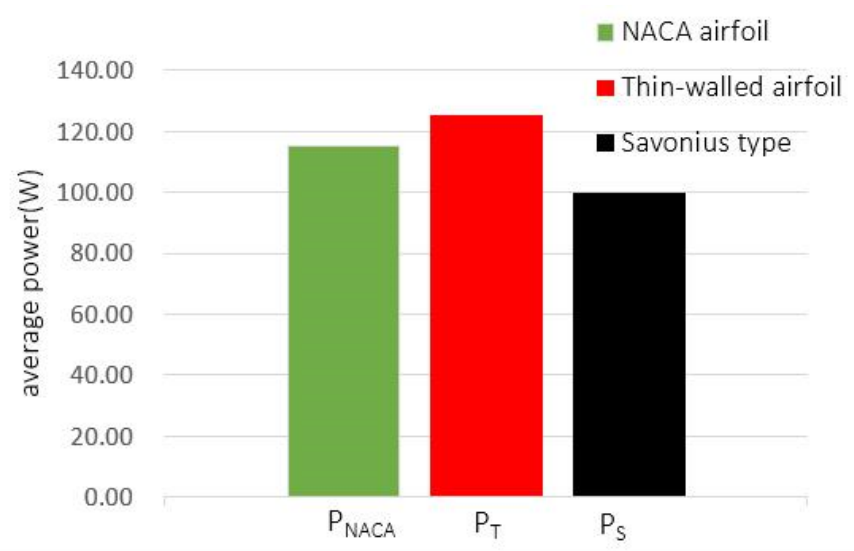

Figure 9. Period of average power of three kinds of turbines with time-varying flow velocity.

\subsection{Turbine Applied Sea Area Tidal}

The sea trial of the tidal current turbine was carried out on the ocean power generation platform. As shown in Figure 10, the platform adopts the form of a catamaran with a platform length of $14 \mathrm{~m}$, a width of $10 \mathrm{~m}$, and a height of $6 \mathrm{~m}$. It adopts single-point anchoring and can automatically convect to rise. We worked normally at low tide, installed tidal power generating turbines between the two hulls, and evenly arranged 3 independent pressurized water tanks on the lower layers of the hulls 
on both sides. The water volume of the pressurized water tanks is adjusted by the submersible pump to realize the platform draft control, which is convenient for the disassembly and testing of the water turbine. Since the mounting bracket of the S-type turbine is different from the other two types of turbine, and it is known from the pool experiment that the S-type turbine is not suitable for the experimental sea area, the sea trial only employed the thin-wall airfoil turbine and NACA airfoil turbine experiments. The radius of the sea test turbine was $1.8 \mathrm{~m}$. The basic parameters are shown in Table 7. As shown in Figure 10, the power shaft of the turbine installation platform is transmitted to the surface power generation device through a double-row chain. The power passes through the dynamic torque sensor and the speed increaser to drive the permanent magnet generator to rotate. The generated electric energy is connected to the load cabinet, and the torque is controlled by the regulation of the load. The control system is equipped with the power flow energy maximum power tracking control module. During the experiment, the load can be adjusted in real time to obtain the maximum captured power [30,31]. In the sea trial experiment, the generator power is not used as the captured power, but the torque and speed are used to calculate the captured power to avoid the influence of the efficiency of the development motor.

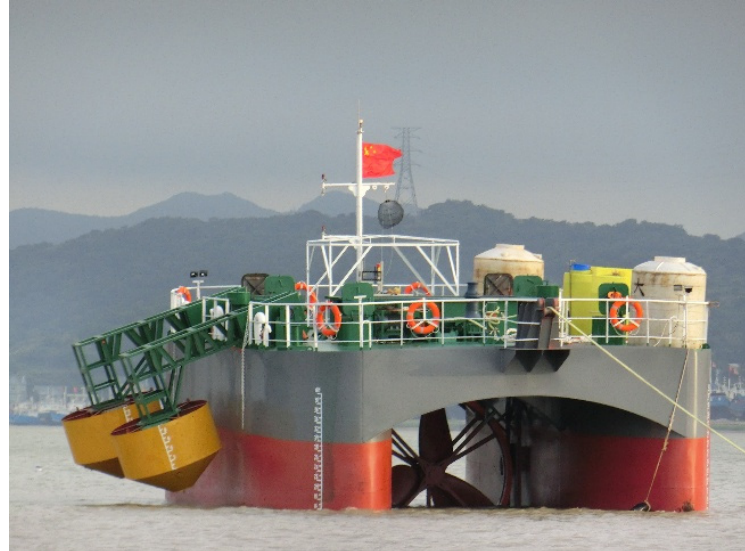

(a)

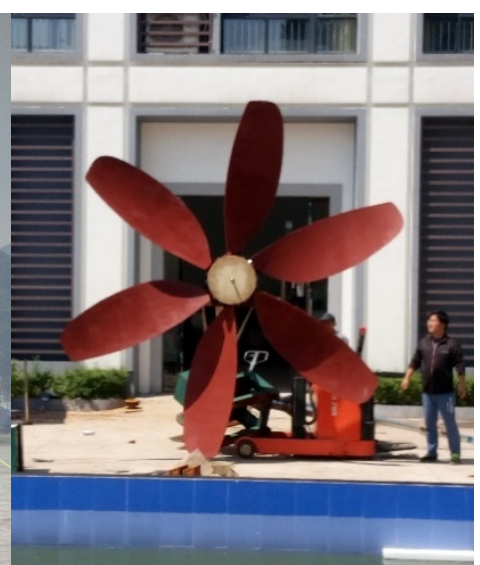

(b)

Figure 10. Physical image of sea trial: (a) Physical image of ocean power generation platform, (b) Physical image of thin-walled airfoil turbine.

Table 7. Basic parameters of ocean power-generation platform.

\begin{tabular}{cccc}
\hline Parameter & Value & Parameter & Value \\
\hline Total length of platform & $14 \mathrm{~m}$ & Wheel diameter & $0.37 \mathrm{~m}$ \\
Total width of platform & $10 \mathrm{~m}$ & Pitch angle & $12^{\circ}$ \\
Total height of platform & $6 \mathrm{~m}$ & Number of blades & 6 \\
Blade radius & $1.8 \mathrm{~m}$ & & \\
\hline
\end{tabular}

During the sea trial, the load was not activated until the flow rate increased and broke through the starting torque, and then the maximum tracking system intervened to adjust the load value to obtain the maximum power; the measurement and control system measures data including flow rate, torque, and speed every $10 \mathrm{~min}$. The experimental record of a tidal current cycle is shown in Figure 11. It can be seen that the flow velocity is basically less than $1 \mathrm{~m} / \mathrm{s}$ during the high tide. The performance of the thin-walled airfoil turbine is better than that of the NACA airfoil turbine. When the tide is low, the flow velocity exceeds $1.2 \mathrm{~m} / \mathrm{s}$, highlighting the short-term advantages of NACA airfoil turbines. Through calculations, the average power of thin-wall airfoil turbines is $1200.96 \mathrm{~W}$, the average power of NACA airfoil turbines is $1121.44 \mathrm{~W}, \mathrm{P}_{\mathrm{T}}>\mathrm{P}_{\mathrm{NACA}}$, which is consistent with the evaluation results of the pool. The trend of the data in the image is in line with the author's guess when conceiving the paper, and the specific conclusions will be presented in the next section. 


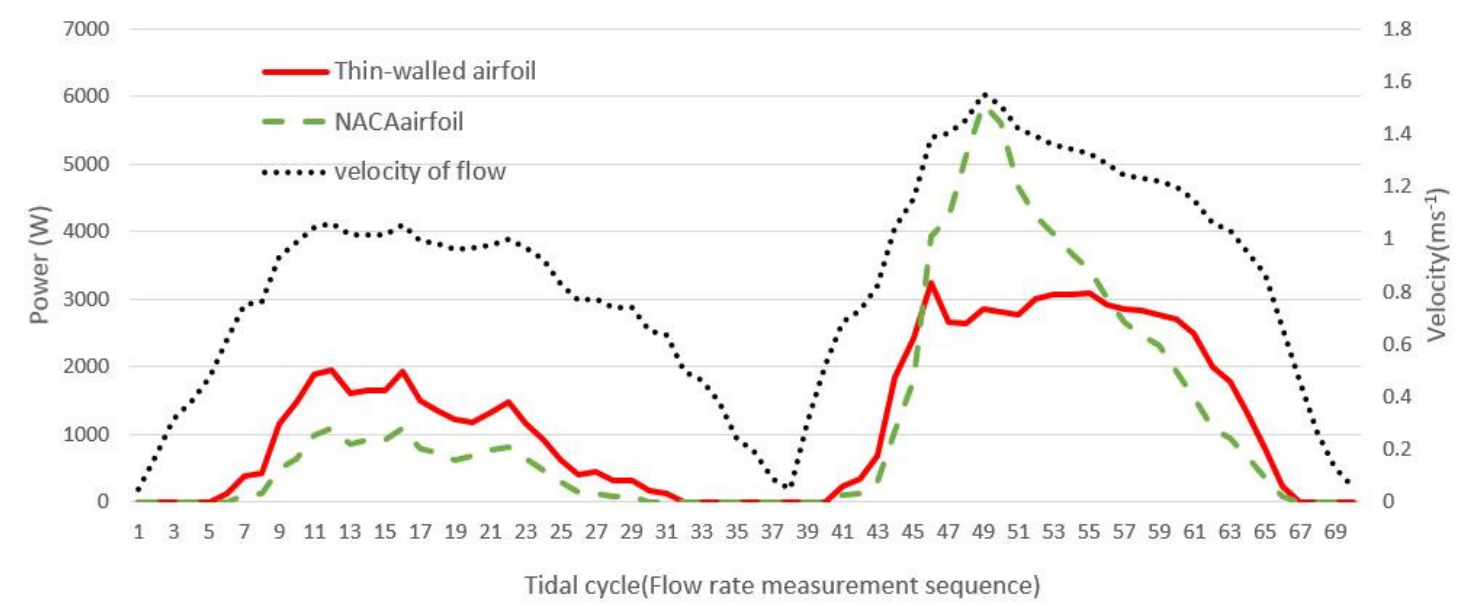

Figure 11. Periodic power and velocity diagram of tidal current.

\section{Conclusions}

In current research on tidal energy turbines, the problem of evaluating the energy capture performance of hydraulic turbines is focused on the design flow rate. It is proposed that the performance evaluation of hydraulic turbines needs to be combined with the application of sea area periodic time-varying flow velocity data, and the statistical division method of tidal cycle flow velocity is given in detail. An evaluation device for constant torque regulation was built. Three types of turbine energy capture performance evaluations were carried out and the corresponding sea trial finally came to the following conclusions:

1. Through experiments to test the energy-harvesting power of the turbines at various flow rates, combining the proportions of each flow rate in the tidal cycle time, and using the weight formula to calculate the average tidal cycle average power and average harvesting efficiency, the overall performance of each turbine in the actual application sea area could be more accurately evaluated.

2. Each type of turbine had the best applicable flow rate range. S-type turbines were more suitable for long-term low-velocity sea areas, NACA airfoil turbines were more suitable for long-term high-velocity waters, and thin-walled airfoil turbines were suitable for the sea between the first two.

3. Turbine performance evaluation cannot be based on the optimal performance under the design flow rate, but should be combined with the actual application sea area flow rate data, and the average power of the tidal current cycle of the technical turbine as the judgment basis, so as to maximize the energy capture efficiency in the application process.

4. When evaluating the performance of the same type of turbine, the evaluation system can be used to change the key parameters of the turbine for testing, and to evaluate the impact of this parameter on the energy capture efficiency in the actual application of the turbine.

Author Contributions: Conceptualization, X.S. and C.J.; methodology, C.J.; validation, C.J. and L.B.; formal analysis, C.J.; data curation, L.B. and H.L.; writing-original draft preparation, C.J.; writing-review and editing, X.S.; visualization, C.J. and H.L.; supervision, X.S.; project administration, J.C. and X.S.; funding acquisition, J.C. All authors have read and agreed to the published version of the manuscript.

Funding: This research was funded by National Key R\&D Project of the Ministry of Science and Technology of the People's Republic of China, grant number 2020YFE0200100.

Conflicts of Interest: The authors declare no conflict of interest.

\section{References}

1. Deng, G.; Zhang, Z. Prospective of development of large-scale tidal current turbine array: An example numerical investigation of Zhejiang, China. Appl. Energy 2020, 264, 114621. [CrossRef]

2. Owen, A. Tidal Current Energy: Origins and Challenges. In Future Energy, 3rd ed.; Elsevier: Amsterdam, The Netherlands, 2020; pp. 357-374. 
3. Suárez-López, M.J.; Espina-Valdés, R. A Review of Software Tools to Study the Energetic Potential of Tidal Currents. Energies 2019, 12, 1673. [CrossRef]

4. Fink, C.W.; Charlier, R. Electrical power generation from ocean currents in the Straits of Florida: Some environmental considerations. Renew. Sustain. Energy Rev. 2009, 13, 2597-2604. [CrossRef]

5. Yücenur, G.N.; Ipekçi, A. SWARA/WASPAS methods for a marine current energy plant location selection problem. Renew. Energy 2021, 163, 1287-1298. [CrossRef]

6. Shadman, M. Ocean Renewable Energy Potential, Technology, and Deployments: A Case Study of Brazil. Energies 2019, 12, 3658. [CrossRef]

7. Hua-Ming, W.; Xiao-Kun, Q.; Lin, C.; Lu-Qiong, T.; Qiao-Rui, W. Numerical study on energy-converging efficiency of the ducts of vertical axis tidal current turbine in restricted water. Ocean Eng. 2020, 210, 107320. [CrossRef]

8. Kim, S.J.; Singh, P.M.; Hyun, B.S.; Lee, Y.H.; Choi, Y.D. A study on the floating bridge type horizontal axis tidal current turbine for energy independent islands in Korea. Renew. Energy 2017, 112, 35-43. [CrossRef]

9. Borg, M.G.; Xiao, Q. A numerical performance analysis of a ducted, high-solidity tidal turbine. Renew. Energy 2020, 159, 663-682. [CrossRef]

10. Ahn, S.; Xiao, Y. Performance prediction of a prototype tidal power turbine by using a suitable numerical model. Renew. Energy 2017, 113, 293-302. [CrossRef]

11. Masters, I.; Williams, A.; Croft, T.N.; Togneri, M.; Edmunds, M.; Zangiabadi, E.; Fairley, I.; Karunarathna, H. A comparison of numerical modelling techniques for tidal stream turbine analysis. Energies 2015, 8, 7833-7853. [CrossRef]

12. Chen, Y.; Lin, B. Experimental study of wake structure behind a horizontal axis tidal stream turbine. Appl. Energy 2017, 196, 82-96. [CrossRef]

13. de Jesus Henriques, T.A.; Hedges, T.S.; Owen, I.; Poole, R.J. The influence of blade pitch angle on the performance of a model horizontal axis tidal stream turbine operating under wave-current interaction. Energy 2016, 102, 166-175. [CrossRef]

14. Alamian, R.; Shafaghat, R.; Amiri, H.A.; Shadloo, M.S. Experimental assessment of a $100 \mathrm{~W}$ prototype horizontal axis tidal turbine by towing tank tests. Renew. Energy 2020, 155, 172-180. [CrossRef]

15. Day, A.H.; Babarit, A. Hydrodynamic modelling of marine renewable energy devices: A state of the art review. Ocean Eng. 2015, 108, 46-69. [CrossRef]

16. Bachant, P.; Wosnik, M. Effects of Reynolds number on the energy conversion and near-wake dynamics of a high solidity vertical-axis cross-flow turbine. Energies 2016, 9, 73. [CrossRef]

17. $\mathrm{Xu}, \mathrm{Q}$.; Liu, H. Development and experiment of a $60 \mathrm{~kW}$ horizontal-axis marine current power system. Energy 2015, 88, 149-156. [CrossRef]

18. Derakhshan, S.; Ashoori, M.; Salemi, A. Experimental and numerical study of a vertical axis tidal turbine performance. Ocean Eng. 2017, 137, 59-67. [CrossRef]

19. Gaurier, B.; Ikhennicheu, M.; Germain, G.; Druault, P. Experimental study of bathymetry generated turbulence on tidal turbine behaviour. Renew. Energy 2020, 156, 1158-1170. [CrossRef]

20. Abutunis, A.; Taylor, G. Experimental evaluation of coaxial horizontal axis hydrokinetic composite turbine system. Renew. Energy 2020, 157, 232-245. [CrossRef]

21. Ma, Y.; Hu, C. Research on the Hydrodynamic Performance of a Vertical Axis Current Turbine with Forced Oscillation. Energies 2018, 11, 3349. [CrossRef]

22. Ren, Y.; Liu, B.; Zhang, T. Influences of winglets on the hydrodynamic performance of horizontal axis current turbines. Appl. Ocean Res. 2019, 92, 101931. [CrossRef]

23. Mosbahi, M.; Elgasri, S.; Lajnef, M.; Mosbahi, B.; Driss, Z. Performance enhancement of a twisted Savonius hydrokinetic turbine with an upstream deflector. Int. J. Green Energy 2020. [CrossRef]

24. Yang, S.; Lin, K. Automatic control loop tuning for permanent-magnet AC servo motor drives. Ieee Trans. Ind. Electron. 2015, 63, 1499-1506. [CrossRef]

25. Neagoe, M.; Saulescu, R.; Jaliu, C.; Simionescu, P.A. A Generalized Approach to the Steady-State Efficiency Analysis of Torque-Adding Transmissions Used in Renewable Energy Systems. Energies 2020, 13, 4568. [CrossRef]

26. Daryabor, F.; Ooi, S.H.; Abu Samah, A.; Akbari, A. Tides and Their Dynamics over the Sunda Shelf of the Southern South China Sea. PLoS ONE 2016, 11, e0162170. [CrossRef] 
27. Han, S.H.; Park, J.S.; Lee, K.S.; Park, W.S.; Yi, J.H. Evaluation of vertical axis turbine characteristics for tidal current power plant based on in situ experiment. Ocean Eng. 2013, 65, 83-89. [CrossRef]

28. Yao, J.; Li, F.; Chen, J.; Yuan, Z.; Mai, W. Parameter Analysis of Savonius Hydraulic Turbine Considering the Effect of Reducing Flow Velocity. Energies 2019, 13, 24. [CrossRef]

29. Tan, J.; Wang, P. Research on analysis of tidal turbine force-related characteristics based on similarity theory. Acta Energ. Sol. Sin. 2019, 40, 456-461.

30. Zhang, H.; Li, M.; Jiang, C. Research on the maximum energy tracking system of tidal current power generation with stable electric energy. Sci. Technol. Eng. 2015, 15, 65-69.

31. Li, Y.; Liu, H.; Lin, Y.; Li, W.; Gu, Y. Design and test of a 600-kW horizontal-axis tidal current turbine. Energy 2019, 182, 177-186. [CrossRef]

Publisher's Note: MDPI stays neutral with regard to jurisdictional claims in published maps and institutional affiliations.

(C) 2020 by the authors. Licensee MDPI, Basel, Switzerland. This article is an open access article distributed under the terms and conditions of the Creative Commons Attribution (CC BY) license (http://creativecommons.org/licenses/by/4.0/). 